\title{
Paste Backfilling Used for Coal Fire Control in Thailand
}

\author{
Manoon Masniyom and Dang Vu Hai \\ Department of Mining and Materials Engineering, Faculty of Engineering, Prince of Songkla University, \\ Hat Yai, Songkhla 90112, Thailand
}

\begin{abstract}
The environmental effects of spontaneous combustion coal seam fires in Mae Moh Lignite Mine in Thailand are subject to a wide array to land surfaces disturbance and air pollution. Air pollution in coal fire is mainly due to the fugitive emission of particulate matter and gases including sulphur dioxide $\left(\mathrm{SO}_{2}\right)$ and oxides of nitrogen (NOx). The traditional methods, executed by fire fighting teams by covering the coal fire areas with soil, excavated burning coal outcrops and injecting water in the coal seam fires are continuously improved. Initiatives to introduce modern techniques, such as backfill placement at fracture and coal seam to cool down the burning coal and cut off air supply. This study is being conducted to investigate the properties of cement and cement kiln dust as backfill materials. As part of this investigation, mixture of materials were prepared by combining cement and cement kiln dust in various ratios of $0.35,0.4,0.45,0.5,0.55$ and 0.6 , to determine their optimal mix proportions for compressive strength development and permeability. The compressive strength of the mixtures of cement and cement kiln dust specimens continued to increase with increasing curing time. It was found the maximum compressive strength of the mixture of $20 \%$ cement and $80 \%$ cement kiln dust was $6.74 \mathrm{MPa}$ mixing a water to solid ratio 0.46 . The permeability of mixtures were decreases when cement kiln dust increases.
\end{abstract}

\section{Introduction}

Mae Moh Lignite Mine is located at Lampang, the northern city of Thailand. It's the largest open-pit mine in Thailand with mining area about $28 \mathrm{~km}^{2}$. The mine geological reserve is about 1,140 million tons of coal (814 million tons mineable). Since 1969, 411 million tons of coal has been extracted. The mine and its mine-mount power plant are operated by Electricity Generating Authority of Thailand. About 16 million tons of coal is harvested annually and supplied to the power plant. This amount of coal can produce electricity accounting for about $10 \%$ of Nation's electric power generation. [1]

The environmental effects of spontaneous coal seam fires in Mae Moh Mine are subject to a wide array to land surfaces disturbance and air pollution. Air pollution in coal fire is mainly due to the fugitive emission of particulate matter and gases including sulphur dioxide $\left(\mathrm{SO}_{2}\right)$ and oxides of nitrogen $\left(\mathrm{NO}_{\mathrm{x}}\right)$ are shown on Figure 1. Locally, coal fires pose serious health and safety risks from toxic fumes and land surface collapses that destroy infrastructure [2]. On a global basis, they contribute large quantities of greenhouse gases to the atmosphere without providing any of the benefits from energy consumption. The traditional methods, executed by fire fighting teams by covering the coal fire areas with soil, excavated burning coal outcrops and injecting water in the coal seam fires are continuously improved. Initiatives to introduce modern techniques, such as paste backfill placement at fracture and coal seam to cool down the burning coal and cut off air supply. Paste backfill is a uniform, low permeability, generally consisting of high solids density mixture. Due to compaction, paste backfill constituent particles do not settle out of suspension at zero flow rates with the fine particles of the matrix forming an annulus around a plug of coarser particles to act as a form of lubrication thereby greatly reducing pipeline frictional resistance.

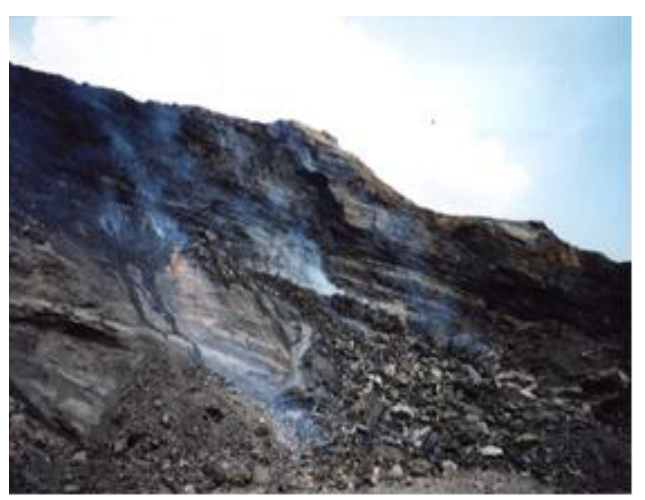

Figure 1. Coal fire in Mae Moh Lignite Mine

Paste backfill uses very small particles of backfill to lubricate the pipeline and therefore requires less water for transportation. Since there is considerably more solid materials in paste backfill, water drainage from the backfill in the stope is generally negligible. A paste backfill may contain between $75 \%$ and $88 \%$ solids (by weight). Cement must always be added to paste backfill 
to prevent the risk of backfill liquefaction [3]. First used during the 1980 's, paste backfill is typically a low permeability, high density solids mixture of aggregate solids and water containing at least $15 \%$ by weight fines material at sizes ranging between minus $20 \mu \mathrm{m}(625$ mesh) to $45 \mu \mathrm{m}$ (325 mesh) content. Because of its higher density state, less water is required to manufacture paste backfill than slurry backfill. When pumped, paste backfill's constituent particles do not settle out of suspension at zero flow rate. This is due to the fact that, once backfill volumetric concentration increases above $50 \%$ solids, particles are no longer free to settle and flow within a pipe becomes that of a plug. Plug flow is the mechanism used to transport highly concentrated paste backfill mixtures. In this state, the bulk of material flows as a core of interlocked and water saturated solid particles surrounded by a thin lubricating layer consisting of a homogeneous mixture made up of water and very fine particles. This high density backfill is able to form a plug as a result of a careful mix design governed by the content of minus 325 mesh fines and the grading of the coarser aggregates.

Cement kiln dust (CKD) is a by-product of cement manufacturing therefore, sometimes considered an industrial waste. A medium size cement plant may produce up to 30,000 tons of CKD annually. Most of the material is disposed off on-site without any further reuse or reclamation [4]. El-Sayed et al. have investigated the effect of CKD on the compressive strength of cement paste and on the corrosion behaviour of embedded reinforcement. The study reported that up to $5 \%$ substitution of CKD by weight of cement had no adverse effect on cement paste strength and on the reinforcement passivity. A similar conclusion was reached in an investigation carried by Batis et al. [5]

\section{Materials and methods}

The materials used in this investigation consisted of Portland cement type I and cement kiln dust from cement plant. Cement kiln dust is a fine, highly alkaline powder. This laboratory test program was implemented to study the relation between the water and solid ratio, compressive strength development and permeability. Particle size analyses were conducted on the backfill sample using a laser particle size analyser and the results are shown on Figure 2. Particle size distribution is one of the most important characteristics of any backfill material is a well-graded particle size distribution [6]. The distribution has the strongest effect on backfill porosity and delivery. In the case of paste backfill, it is the portion of the materials finer than $20 \mu \mathrm{m}$, which seems to have the most pronounced effect on pump ability.

Portland cement type I was replaced by cement kiln dust at percentages of $0,5,10,15$ and 20 by weight of cementitious materials, and all mixture proportions of paste backfill are shown in Table 1.

The backfill materials, cement, cement kiln dust and water were first mixed and homogenized in a double spiral mixer to produce the paste backfill mixtures. After that, slump tests, according to ASTM C 143-90, were done to evaluate the transportability of the backfill. The pulp density and the water/solid ratios (w/s) were also determined to evaluate the water demand of the paste backfill. The paste backfill mixtures produced were then poured into curing cylinders, $10 \mathrm{~cm}$ in diameter and 20 $\mathrm{cm}$ high. These samples were then sealed and cured in a humidity chamber at approximately $80 \%$ humidity and 23 oC. After curing times of 28 days, the uniaxial compressible strength (UCS) according to ASTM C 39, the specific gravity, particle size, bulk density, water content and permeability of each paste backfill sample were determined.

Table 1. Mixture proportions of paste backfill

\begin{tabular}{|c|c|c|c|c|c|}
\hline Materials & Mix 1 & Mix 2 & Mix 3 & Mix 4 & Mix 5 \\
\hline Cement (\%) & 0 & 5 & 10 & 15 & 20 \\
\hline CKD (\%) & 100 & 95 & 90 & 85 & 80 \\
\hline
\end{tabular}

\section{Results and discussions}

\subsection{Paste backfill materials characteristics}

Table 2 and Figure 2 show the physical characterize of materials; specific gravity determination, particle size measurement, bulk density, water content and permeability. During the investigation water and solid ratios (w/s) $0.6,0.55,0.5,0.45,0.4$ and 0.35 (by weight) were chosen for various mixtures by vicat test. Water and solid ratio below 0.35 and above 0.55 could not be mixed in a satisfactory way.

Table 2. Physical characteristics of backfill materials

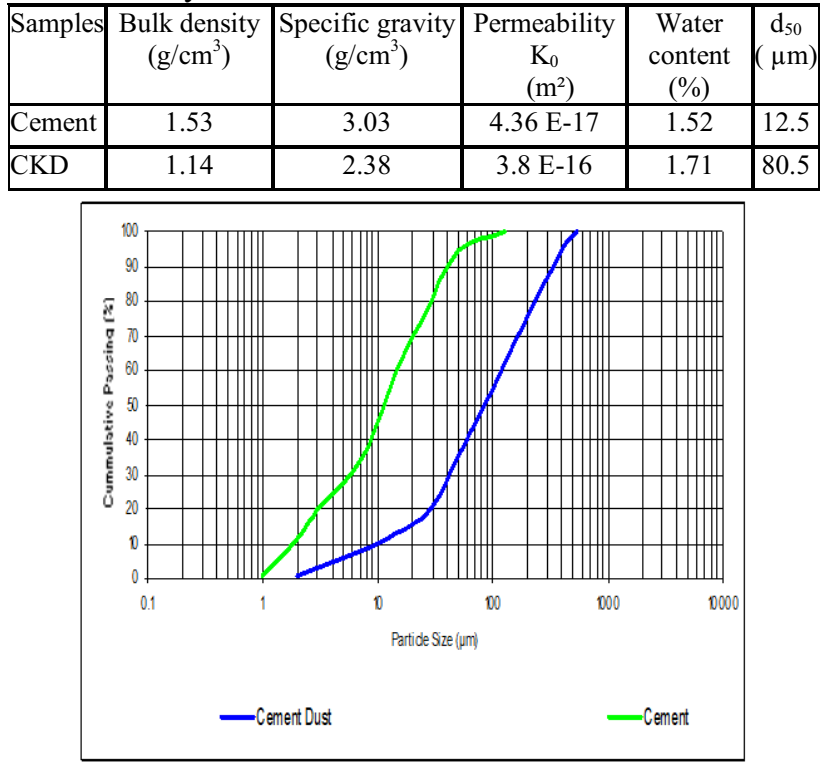

Figure 2. Particle size distribution of backfill materials

\subsection{Chemical properties}


Chemical composition was determined by using X-ray fluorescence spectrometer (XRF). The results are shown in Table 3. Total lime $(\mathrm{CaO})$ constitutes more than $50 \%$ of $\mathrm{CKD}$ composition. It is relatively high in alkaline content $\left(\mathrm{K}_{2} \mathrm{O}\right.$ and $\left.\mathrm{Na}_{2} \mathrm{O}\right)$.

Table 3. Chemical composition of backfill

\begin{tabular}{|c|c|c|}
\hline Chemical composition (\%) & Cement dus & Cement \\
\hline $\mathrm{SiO}_{2}$ & 13.5 & 21.3 \\
\hline $\mathrm{Al}_{2} \mathrm{O}_{3}$ & 4.34 & 4.64 \\
\hline $\mathrm{Fe}_{2} \mathrm{O}_{3}$ & 2.72 & 3.57 \\
\hline $\mathrm{CaO}$ & 52.33 & 62.45 \\
\hline $\mathrm{MgO}$ & 2.71 & 2.43 \\
\hline $\mathrm{Na}_{2} \mathrm{O}$ & 0.15 & 0.2 \\
\hline $\mathrm{K}_{2} \mathrm{O}$ & 2.98 & 0.5 \\
\hline $\mathrm{MnO}_{2}$ & - & 0.04 \\
\hline $\mathrm{P}_{2} \mathrm{O}_{5}$ & - & 0.04 \\
\hline $\mathrm{TiO}_{2}$ & - & 0.02 \\
\hline $\mathrm{SO}_{3}$ & 1 & 2.7 \\
\hline
\end{tabular}

\subsection{Uniaxial compression tests}

For the study, A total of 90 specimens were tested by uniaxial compression machine to investigate compressive strength and subjected to uniaxial compression tests using a mechanical press having a normal loading capacity maximum of $1,000 \mathrm{kN}$. The results are shown in Figure 3. The compressive strength of the cement and mixtures of cement and cement kiln dust specimens continued to increase with increasing curing time. It was found the maximum compressive strength of the mixture of $20 \%$ cement and $80 \%$ dust filter (Mix 5) was 6.74 MPa mixing a water to solid ratio 0.46 .

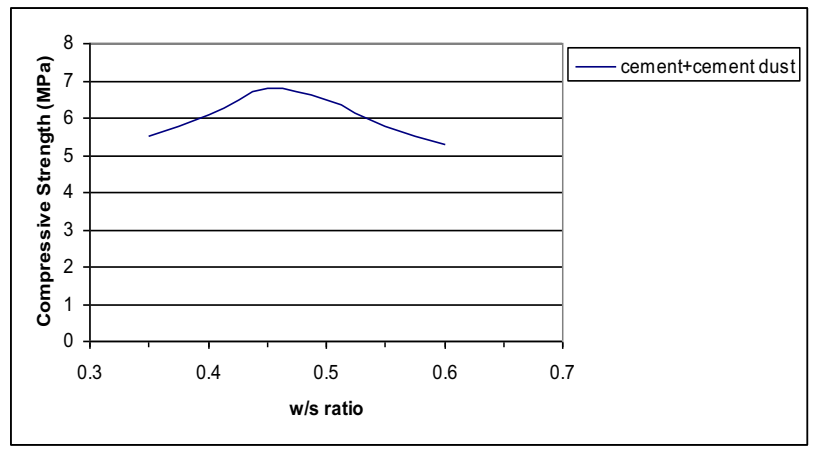

Figure 3. Compressive strength of paste backfill mixtures at 28 day
The mixtures of backfill are mixed at the mixing area to be used to fight the coal fire. The paste backfill was placed to coal seam fracture and distributed around the source of the coal fire are shown in Figure 4. The basic behaviour of coal fires depends on the transport and supply of oxygen in the subsurface and therefore mainly on the permeability, thermal conductivity and specific heat capacity of the material. Because of this, systematic experiments, carried out in the laboratory on backfill samples, yield the functional dependency of these parameters of the material. The experiments have shown that if backfill mixture of cement, cement kiln dust and water are placed into high temperature zones of burning coal or even used for rewetting an oxygen isolating sand cover, water will evaporate and the cement will solidification. Besides the cooling effect, the pores of the permeable rock will be partially closed by binder. The resulting lower permeability will prevent further oxygen transport.

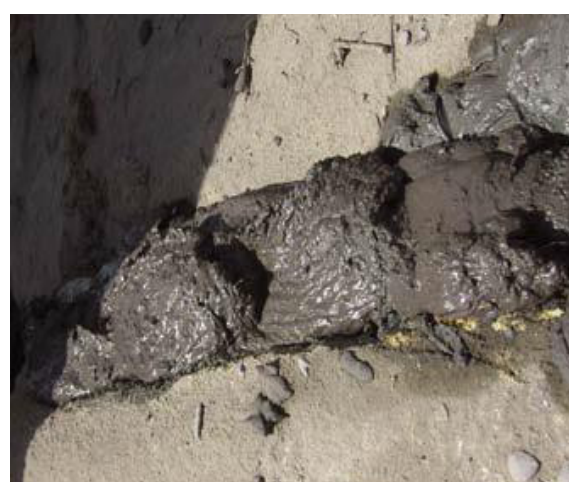

Figure 4. Paste backfill placed to coal seam fracture

In general, higher backfill strengths are achieved by adding more binder, so costs are higher. However, any required strength can usually be achieved using a number of different mixes, so testing is necessary to identify the optimum mix from the available materials. The relative prices of portland cement and cement kiln dust, the costeffectiveness of chemical additives and the potential savings from disposal of tailings or industrial waste as backfill must all be incorporated into the determination of operating costs.

\section{Conclusions}

The paste backfill mixture is a very low permeability and high density that can placed to the coal seam and distributed around the source of the coal fire. The resulting lower permeability will prevent further oxygen transport and control coal fire. The permeability of mixtures were decreases when cement kiln dust increases. The compressive strength of the mixtures of cement and cement kiln dust specimens continued to increase with increasing curing time. Furthermore backfilling voids enhances the stability and improving safety of the mine. 
1. A. Laksanayothina and W. Ariyawong, Groundwater treatment of Thailand's Mae Moh lignite mine, Proceeding of International Conference on Environmental Issues in Mining and Natural Resources Development (EMNR):November 2016, pp.2-6 (2016)

2. L. Jing, S. Voight, C. Kunzer, Y. Bol, Z. Jianzhoung, Z. Yianmin, K. Bing, and Z. Songmeil, The Progress in Detecting of Coal Fire on Remote Sensing, The First Result of The Joint SINO-German Research Project on Innovative Technologies for Exploration, Extinction and Monitoring of Coal Fires in North China, Proc. 2005 Dragon Symposium "Mid-Term Results", Santorini, Greece 27 June - 1 July, 7 p. (2005)

3. Y. Potvin, E. Thomas and A. Fourie, Handbook on Mine Fill, Australian Centre for Geomechanics, 179 pp. (2005)
4. H.A. El Sayed, N.A. Gabr, S. Hanafi and M.A. Mohran, Reutilization of by-pass kiln dust in cement manufacture, International Conference on Blended Cement in Construction, Sheffield, UK, September 1991.

5. G. Batis, E. Rakanta, E. Sideri, E. Chaniotakis and A. Papageorgiou, Advantages of simultaneous use of cement kiln dust and blast furnace slag, International Conference on Challenges of Concrete Construction, University of Dundee, Dundee, UK, September. (2002)

6. A.G. Grice, Recent Minefill Developments in Australia, Proceedings of the 7th international symposium on mining with backfill, Seattle, Washington, pp. 351-358. (2001) 